\title{
Manejo do solo, água e nitrogênio no cultivo de feijão
}

\author{
Orivaldo Arf ${ }^{(1)}$, Ricardo Antonio Ferreira Rodrigues ${ }^{(2)}$, Marco Eustáquio de Sá( ${ }^{(1)}$, Salatier Buzetti( ${ }^{(2)}$ \\ e Vagner do Nascimento(1)
}

\begin{abstract}
(1)Universidade Estadual Paulista (Unesp), Fac. de Engenharia de llha Solteira, Dep. de Fitotecnia, Tecnologia de Alimentos e Sócio-Economia, Caixa Postal 31, CEP 15385-000 Ilha Solteira, SP. E-mail: arf@agr.feis.unesp.br, mesa@agr.feis.unesp.br, vagner@agr.feis.unesp.br (2)Unesp, Fac. de Engenharia de Ilha Solteira, Dep. de Fitossanidade, Engenharia Rural e Solos. E-mail: ricardo@agr.feis.unesp.br, sbuzetti@agr.feis.unesp.br
\end{abstract}

\begin{abstract}
Resumo - O objetivo deste trabalho foi avaliar o efeito do preparo e não preparo do solo, de doses de $\mathrm{N}$ aplicadas em cobertura e da irrigação na produtividade do feijoeiro cv. IAC Carioca Eté. O delineamento experimental foi o de blocos casualizados em esquema fatorial com quatro repetições. Os tratamentos constituíram-se da combinação de três lâminas de água, com preparo do solo com arado de aiveca, com grade pesada e sem preparo (plantio direto) e com 0, 30, 60, 90 e $120 \mathrm{~kg} \mathrm{ha}^{-1} \mathrm{de} \mathrm{N}$ aplicados em cobertura aos 15 dias após a emergência das plantas. A irrigação foi realizada com um sistema fixo de irrigação convencional por aspersão e no manejo de água foram utilizados diferentes coeficientes de cultura $(\mathrm{Kc})$ distribuídos em períodos compreendidos entre a emergência e a colheita. A menor lâmina de água propiciou produtividade de grãos semelhante à das outras lâminas, mas com menor custo. O preparo do solo com arado de aiveca não diferenciou do preparo com grade aradora e proporcionou maior produtividade de grãos em relação ao plantio direto. A adubação nitrogenada não afetou a produtividade de grãos.
\end{abstract}

Termos para indexação: Phaseolus vulgaris, arado de aiveca, grade aradora, irrigação por aspersão, adubo nitrogenado.

\section{Soil, water and nitrogen management in common bean cultivation}

\begin{abstract}
The appropriate cultural management enhance the plant efficiency on available resource utilization. This study aimed to evaluate the IAC Carioca Eté cultivar common bean performance as a function of soil management, sidedressing nitrogen rates and water level management. A randomized block design in a factorial scheme with four repetitions was used. The treatments were constituted by combination of three water levels, three soil management (moldboard plow + leveling disc harrow, heavy disc harrow + leveling disc harrow, and no tillage) and sidedressing nitrogen rates applied at 15 days after plant emergency $\left(0,30,60,90\right.$, and $\left.120 \mathrm{~kg} \mathrm{ha}^{-1}\right)$. It was also used a sprinkle irrigation system and different cultural coefficients $(\mathrm{Kc})$ for water management between plant emergency and harvest. The smallest water level showed grain yield similar to other levels but with the advantage of being cheaper. The soil tillage with moldboard plow allowed higher grain yield in relation to no till system and that was similar to the preparation with heavy disc harrow. The sidedressing nitrogen fertilization did not interfere in the grain yield.
\end{abstract}

Index terms: Phaseolus vulgaris, moldboard ploughs, disc harrows, sprinkler irrigation, nitrogen fertilizers.

\section{Introdução}

O fornecimento de quantidades adequadas de água é um dos fatores fundamentais na produção das culturas. Para tanto, a água em excesso deve ser armazenada de modo a estar disponível em períodos de estiagem, mesmo sob condições irrigadas. Os solos sob cultivo devem ser preparados de modo a alterar o mínimo possível as suas características físicas e químicas originais, especialmente aquelas que afetam a infiltração e retenção de água, como porosidade e agregação (Castro et al., 1987).
A compactação do solo afeta a aeração por causa das modificações na estrutura do solo e na drenagem da água. O efeito imediato é a redução no volume de macroporos, reduzindo a difusão da água e dos gases, e dificultando o crescimento das raízes (Pedroso \& Corsini, 1983). O preparo sucessivo do solo com grade aradora, além de ocasionar excessiva desintegração física e preparo apenas superficial do solo, pode levar à formação de uma camada impermeável conhecida como sola de grade (Fornasieri Filho \& Fornasieri, 1993). 
Barros \& Hanks (1997) observaram que a cobertura do solo aumentou a produtividade e a eficiência no uso de água pelo feijoeiro. Stone \& Silveira (1999) verificaram que o preparo com aiveca propiciou menor resistência à penetração, ao longo do perfil; com o uso da grade aradora houve a formação de uma camada mais compacta entre 10 e $24 \mathrm{~cm}$ de profundidade e no sistema de plantio direto houve maior compactação até $15-22 \mathrm{~cm}$ de profundidade. Esses autores verificaram ainda que a distribuição do sistema radicular em profundidade foi mais uniforme no preparo com arado; no preparo com grade $60 \%$ das raízes se concentraram na camada de $0-10 \mathrm{~cm}$ e no plantio direto, nos primeiros $20 \mathrm{~cm}$.

Buzetti et al. (1992) constataram aumento linear na produtividade de grãos da ordem de $4,33 \mathrm{~kg}$ de grãos para cada kg de $\mathrm{N}$ aplicado. O parcelamento da aplicação (20 e 40 dias após a emergência) aumentou a massa e a produtividade de grãos. Silveira \& Damasceno (1993) verificaram aumento na massa de matéria seca, teor e conteúdo de $\mathrm{N}$ na parte aérea e de vagens por planta com a aplicação de doses crescentes de $\mathrm{N}$. A produtividade de grãos obedeceu a uma função quadrática, atingindo o máximo com $72 \mathrm{~kg} \mathrm{ha}^{-1}$ de $\mathrm{N}$.

Carvalho et al. (2001), estudando parcelamentos $(0$ e $0 ; 0$ e $75 ; 15$ e $60 ; 30$ e $45 ; 45$ e $30 ; 60$ e 15 e 75 e $0 \mathrm{~kg} \mathrm{ha}^{-1}$ de $\mathrm{N}$, respectivamente, na semeadura e em cobertura) em feijão de inverno, na região de Selvíria, MS, concluíram que a aplicação de $75 \mathrm{~kg} \mathrm{ha}^{-1}$ de N proporcionou, em média, incrementos de $38 \%$ na produtividade; o $\mathrm{N}$ aplicado na semeadura e em cobertura não teve efeito significativo na produtividade.

Trabalhos anteriores apresentam resultados contraditórios quanto à redução da produtividade decorrente do estresse hídrico nos diversos estádios de desenvolvimento. Assim, Mac Kay \& Eanes (1962) consideram como período crítico o pré-florescimento; Kattan \& Fleming (1956) indicam que o período crítico é o florescimento; Doorenbos \& Pruitt (1976) e Bergamaschi et al. (1988) afirmam que o florescimento e o aparecimento das vagens são os períodos mais críticos. Por sua vez, solos muito úmidos propiciam condições de má aeração ao sistema radicular, além de aumento da incidência de doenças. Assim, segundo Moreira et al. (1988), o excesso de água provoca deficiência de oxigênio, levando a uma concentração inadequada desse elemento na planta e redução da atividade microbiana do solo. Segundo esses autores, o consumo de água pelo feijoeiro depende do estádio de desenvolvimento, das condições do solo, época de cultivo e das condições climáticas. De acordo com Doorenbos \& Kassam (1979), a necessidade de água do feijoeiro com ciclo de 60 a 120 dias varia entre 300 a $500 \mathrm{~mm}$ para obtenção de alta produtividade.

O déficit de água no período vegetativo reduz o crescimento das plantas, que podem se recuperar se a irrigação for reiniciada, mas não apresentarão a mesma produtividade das plantas irrigadas adequadamente durante todo o ciclo. A água de irrigação deve atender à exigência hídrica da planta, que varia, principalmente, com as condições de clima do local, época de semeadura, cultivares e estádios de desenvolvimento da planta (Silveira \& Stone, 1998).

O objetivo deste trabalho foi avaliar o efeito do preparo e não preparo do solo, de doses de $\mathrm{N}$ aplicadas em cobertura e da irrigação na produtividade de grãos do feijoeiro cv. IAC Carioca Eté.

\section{Material e Métodos}

O trabalho foi realizado no Município de Selvíria, MS, aproximadamente a $51^{\circ} 22^{\prime}$ de longitude Oeste de Greenwich e $20^{\circ} 22^{\prime}$ de latitude Sul, com altitude de $335 \mathrm{~m}$. O solo do local é do tipo Latossolo Vermelho distrófico típico argiloso, A moderado, hipodistrófico, álico, caulinítico, férrico, compactado, muito profundo, moderadamente ácido (Embrapa, 1999). A precipitação média anual é de $1.370 \mathrm{~mm}$, a temperatura média anual é de $23,5^{\circ} \mathrm{C}$ e a umidade relativa média anual do ar oscila entre $70 \%$ e $80 \%$.

Antes da instalação do experimento, foram coletadas amostras compostas de 20 subamostras de solo da área experimental, na profundidade de $0-0,20 \mathrm{~m}$. A análise química das amostras compostas revelou os seguintes valores: $\mathrm{MO}, 21 \mathrm{~g} \mathrm{dm}^{-3} ; \mathrm{P}$ (resina), $18 \mathrm{mg} \mathrm{dm}^{-3} ; \mathrm{pH}$ $\left(\mathrm{CaCl}_{2}\right), 5,0 ; \mathrm{K}, \mathrm{Ca}, \mathrm{Mg}$ e $\mathrm{H}+\mathrm{Al}, 1,6,22,15 \mathrm{e}$ $34 \mathrm{mmol}_{\mathrm{c}} \mathrm{dm}^{-3}$, respectivamente e $\mathrm{V}, 53 \%$.

Odelineamento experimental foi o de blocos casualizados com as parcelas dispostas em esquema fatorial, com 45 tratamentos constituídos pela combinação de duas modalidades de preparo do solo (arado de aiveca + grade niveladora e grade pesada + grade niveladora) e plantio direto, três lâminas de água aplicadas por aspersão (L1: coeficiente da cultura $\left(\mathrm{Kc}_{1}\right)$ + precipitação; L2: coeficiente da cultura $\left(\mathrm{Kc}_{2}\right)+$ precipitação; L3: coeficiente da cultura $\left(\mathrm{Kc}_{3}\right)+$ precipitação) e doses de $\mathrm{N}$ em co- 
bertura $\left(0,30,60,90\right.$ e $\left.120 \mathrm{~kg} \mathrm{ha}^{-1}\right)$, com quatro repetições. As parcelas foram constituídas por cinco linhas de $6 \mathrm{~m}$ de comprimento e a área útil de três linhas centrais, desprezando-se $0,50 \mathrm{~m}$ em ambas as extremidades de cada linha.

O fornecimento de água foi realizado por um sistema fixo de irrigação convencional por aspersão com precipitação média de $3,3 \mathrm{~mm} \mathrm{~h}^{-1}$ nos aspersores. A reposição de água foi realizada quando a evapotranspiração da cultura (ETc) acumulada atingia valores próximos da água disponível do solo (ADS) preestabelecidos. A evaporação de água (ECA) foi obtida diariamente do tanque classe A instalado no Posto Meteorológico distante $500 \mathrm{~m}$ da área experimental. O coeficiente do tanque classe A (Kp) utilizado foi o proposto por Doorenbos \& Pruitt (1976).

No manejo de água da cultura foram utilizados coeficientes de cultura $(\mathrm{Kc})$ das fases de desenvolvimento: germinação - folhas primárias $\left(\mathrm{V}_{0}-\mathrm{V}_{2}\right)$; primeira folha trifoliada - terceira folha trifoliada $\left(\mathrm{V}_{3}-\mathrm{V}_{4}\right)$; préfloração - formação de vagens $\left(\mathrm{R}_{5}-\mathrm{R}_{7}\right)$; enchimento de vagens $\left(\mathrm{R}_{8}\right)$ e maturação $\left(\mathrm{R}_{9}\right)$ (Fernandez et al., 1986) (Tabela 1). Os valores dos coeficientes de cultura $\left(\mathrm{Kc}_{2}\right)$ utilizados na lâmina 2 foram os propostos por Doorenbos \& Kassam (1979). Nas lâminas 1 e 3 os valores dos coeficientes de cultura $\mathrm{Kc}_{1}$ e $\mathrm{Kc}_{3}$ foram, respectivamente, $25 \%$ inferior e $25 \%$ superior em relação ao $\mathrm{Kc}_{2}$.

$\mathrm{O}$ preparo do solo, dependendo do tratamento, foi realizado com aiveca ou grade aradora e duas gradagens de nivelamento, sendo a última realizada às vésperas da semeadura. No plantio direto a dessecação da cobertura foi realizada com a aplicação de $1.560 \mathrm{~g} \mathrm{ha}^{-1}$ do i.a. de glifosato.

A adubação nos sulcos de semeadura foi calculada

Tabela 1. Valores de coeficiente da cultura $(\mathrm{Kc})$ utilizados nas diferentes fases de desenvolvimento do feijoeiro de acordo com as lâminas de água aplicadas por aspersão.

\begin{tabular}{cccccc}
\hline $\begin{array}{c}\text { Lâmina de } \\
\text { água }^{(1)}\end{array}$ & \multicolumn{5}{c}{ Fases de desenvolvimento $^{(2)}$} \\
\cline { 2 - 6 } & $\mathrm{V}_{\mathrm{O}}-\mathrm{V}_{2}$ & $\mathrm{~V}_{3}-\mathrm{V}_{4}$ & $\mathrm{R}_{5}-\mathrm{R}_{7}$ & $\mathrm{R}_{8}$ & $\mathrm{R}_{9}$ \\
\hline L1 & 0,23 & 0,53 & 0,79 & 0,56 & 0,19 \\
L2 & 0,30 & 0,70 & 1,05 & 0,75 & 0,25 \\
L3 & 0,38 & 0,88 & 1,31 & 0,94 & 0,31 \\
\hline
\end{tabular}

${ }^{(1)} \mathrm{L} 1$ : coeficiente da cultura $\left(\mathrm{Kc}_{1}\right)+$ precipitação; $\mathrm{L} 2: \mathrm{Kc} \mathrm{c}_{2}+$ precipitação; L3: $\mathrm{Kc}_{3}+$ precipitação. ${ }^{(2)}$ Fases de desenvolvimento (Fernandez et al., 1986): $\mathrm{V}_{0}-\mathrm{V}_{2}$ : germinação - folhas primárias; $\mathrm{V}_{3}-\mathrm{V}_{4}$ : primeira folha trifoliada - terceira follha trifoliada; $\mathrm{R}_{5}-\mathrm{R}_{7}$ : pré-floração - formação de vagens; $R_{8}$ : enchimento de vagens; $R_{9}$ : maturação. de acordo com a análise do solo e as recomendações de Ambrosano et al. (1996). Aplicaram-se $240 \mathrm{~kg} \mathrm{ha}^{-1} \mathrm{da}$ fórmula $4-30-10+0,3 \%$ de $\mathrm{Zn}$. A semeadura foi realizada em 25/4/2001 e 7/5/2002, utilizando a cultivar IAC Carioca Eté, com espaçamento de 0,45 m (2001) e $0,50 \mathrm{~m}$ (2002) entre linhas, e sementes necessárias para a obtenção de $12-13$ plantas $\mathrm{m}^{-1}$ após a emergência. Antes da semeadura, as sementes foram tratadas com $100 \mathrm{~g}$ (i.a.) de benomyl por $100 \mathrm{~kg}$. A adubação nitrogenada (uréia) em cobertura foi realizada 15 dias após a emergência das plantas.

No controle de plantas daninhas aplicou-se, 20 dias após a emergência, o herbicida fluazifop-p-butil + fomesafen $\left(200+250 \mathrm{~g} \mathrm{ha}^{-1}\right.$ do i.a.). Os demais tratos culturais foram os normalmente recomendados à cultura do feijão na região.

Por ocasião do florescimento pleno das plantas foram coletadas 10 plantas da área útil das parcelas, as quais foram secadas em estufa de ventilação forçada à temperatura média de $60-70^{\circ} \mathrm{C}$, até peso constante. Em seguida foram pesadas e moídas em moinho do tipo Willey para determinação do teor de $\mathrm{N}$, conforme Sarruge \& Hagg (1974).

Foram coletadas 10 plantas, em local predeterminado de cada parcela, para determinação do número de vagens e de grãos por planta, número médio de grãos por vagem e massa de 100 grãos. A produtividade de grãos foi obtida pela colheita das demais plantas da área útil das parcelas, que após secadas, foram trilhadas manualmente, os grãos abanados, pesados e determinada sua umidade, que, em seguida, foi corrigida para $13 \%$ (base úmida). Os dados obtidos foram submetidos à análise de variância e as médias comparadas pelo teste de Tukey a 5\% de probabilidade. Em relação às doses de $\mathrm{N}$ utilizou-se a análise de regressão.

\section{Resultados e Discussão}

Nos fatores estudados, houve efeito significativo isolado para algumas características avaliadas. Houve interação significativa entre lâminas de água e doses de $\mathrm{N}$ na massa de matéria seca de plantas em 2001 e entre lâminas de água e preparo do solo na massa de 100 grãos em 2001 e número de grãos por vagem em 2002.

A emergência das plantas ocorreu aos seis dias e a colheita aos 94 (2001) e 87 dias (2002) após a semeadura, respectivamente. Houve adequada precipitação pluvial no período de cultivo $(126 \mathrm{~mm})$ em 2001 e me- 
nor quantidade de chuva (35 mm) em 2002 (Tabela 2). De acordo com Doorenbos \& Kassam (1979), a necessidade de água do feijoeiro varia entre 300 e $500 \mathrm{~mm}$ para obtenção de alta produtividade. Todas as parcelas receberam abaixo dessa quantidade de água.

$\mathrm{Na}$ fase final de enchimento de grãos $\left(\mathrm{R}_{8}\right)$, foi necessário interromper a irrigação por causa de um ataque de mofo-branco, principalmente nas parcelas com plantio direto. Entretanto, não houve prejuízo para o completo enchimento de grãos no primeiro ano de cultivo, pois nessa época os dias curtos e a temperatura mais amena propiciam manutenção de umidade no solo por um período maior. Já no segundo ano, provavelmente o enchimento de grãos pode ter sido afetado, pois os valores obtidos para a massa de 100 grãos estão um pouco abaixo da média encontrada para essa cultivar em condições normais de cultivo. Por outro lado, a interrupção

Tabela 2. Disponibilidade de água proveniente da precipitação pluvial e irrigação por aspersão durante o ciclo do feijoeiro.

\begin{tabular}{|c|c|c|c|c|c|c|}
\hline \multirow{2}{*}{$\begin{array}{l}\text { Lâmina de } \\
\text { água }^{(1)}\end{array}$} & \multicolumn{2}{|c|}{ Precipitação (mm) } & \multicolumn{2}{|c|}{ Irrigação (mm) } & \multicolumn{2}{|c|}{ Total $(\mathrm{mm})$} \\
\hline & 2001 & 2002 & 2001 & 2002 & 2001 & 2002 \\
\hline L1 & 126 & 35 & 89 & 115 & 215 & 150 \\
\hline L2 & 126 & 35 & 125 & 178 & 251 & 213 \\
\hline L3 & 126 & 35 & 161 & 219 & 287 & 254 \\
\hline
\end{tabular}

${ }^{(1)} \mathrm{L} 1:$ coeficiente da cultura $\left(\mathrm{Kc}_{1}\right)+$ precipitação; $\mathrm{L} 2: \mathrm{Kc}_{2}+$ precipitação; L3: $\mathrm{Kc}_{3}+$ precipitação. da irrigação ocorreu quando a cultura não mais se encontrava em período considerado crítico de acordo com Kattan \& Fleming (1956), Mac Kay \& Eanes (1962), Doorenbos \& Pruitt (1976) e Bergamaschi et al. (1988).

No primeiro ano de cultivo, o preparo do solo com grade aradora ou com arado de aiveca apresentou maior massa de matéria seca de plantas do que o plantio direto (Tabela 3). Com o desdobramento de doses de $\mathrm{N}$ dentro de lâminas de água, nas lâminas $\mathrm{L}_{2} \mathrm{e} \mathrm{L}_{3}$ houve aumento nos valores de massa de matéria seca de plantas em razão das doses de $\mathrm{N}$ utilizadas e os dados se ajustaram a funções lineares (Tabela 4). Já para lâminas de água dentro de doses de $\mathrm{N}$, houve efeito nas doses de 0,30 e $120 \mathrm{~kg} \mathrm{ha}^{-1}$ de $\mathrm{N}$, em que a lâmina $\mathrm{L}_{1}$ apresentou, de maneira geral, maior massa de matéria seca. Talvez esse comportamento possa ser explicado pela maior disponibilidade de oxigênio no solo para o desenvolvimento do sistema radicular, por causa do menor volume de água via irrigação em relação às lâminas $L_{2}$ e $L_{3}$. Já em 2002, a matéria seca de plantas foi influenciada apenas pelas doses de $\mathrm{N}$ e os dados se ajustaram à função linear $\mathrm{y}=6,5033+0,0111 \mathrm{x}$.

Quanto ao teor de $\mathrm{N}$ total das plantas, houve diferenças em relação ao preparo do solo somente em 2001, quando o plantio direto apresentou os maiores valores, $o$ que pode ter ocorrido em razão desse tratamento ter apresentado a menor quantidade de massa de matéria

Tabela 3. Massa da matéria seca de plantas, teor de $\mathrm{N}$ nas folhas e número de vagens por planta em feijoeiro de inverno em razão de diferentes lâminas de água aplicadas por aspersão, de diferentes preparos do solo e de doses de $\mathrm{N}$ aplicadas em cobertura. Selvíria, MS, 2001 e $2002^{(1)}$.

\begin{tabular}{|c|c|c|c|c|c|c|}
\hline \multirow[t]{2}{*}{ Tratamento } & \multicolumn{2}{|c|}{ Massa de matéria seca $\left(\mathrm{g}\right.$ planta $\left.{ }^{-1}\right)$} & \multicolumn{2}{|c|}{$\mathrm{N}$ nas folhas $\left(\mathrm{g} \mathrm{kg}^{-1}\right)$} & \multicolumn{2}{|c|}{ Vagens por plantas $\left(\mathrm{n}^{\circ}\right)$} \\
\hline & 2001 & 2002 & 2001 & 2002 & 2001 & 2002 \\
\hline \multicolumn{7}{|l|}{ Lâminas de água ${ }^{(2)}$} \\
\hline L1 & 5,72 & 7,03 & 34,9 & 31,3 & 11,0 & 7,1 \\
\hline $\mathrm{L} 2$ & 5,99 & 7,28 & 35,4 & 31,5 & 10,5 & 7,1 \\
\hline L3 & 5,55 & 7,20 & 36,0 & 30,9 & 10,9 & 6,6 \\
\hline \multicolumn{7}{|l|}{ Preparo do solo } \\
\hline Plantio direito & $5,47 \mathrm{~b}$ & 7,41 & $36,9 \mathrm{a}$ & 30,3 & $10,0 \mathrm{~b}$ & $6,4 b$ \\
\hline Grade pesada & $6,39 \mathrm{a}$ & 7,01 & $34,4 b$ & 32,0 & $11,4 \mathrm{a}$ & $6,9 \mathrm{ab}$ \\
\hline Arado de aiveca & $6,41 \mathrm{a}$ & 7,09 & $34,9 b$ & 31,4 & $11,2 \mathrm{ab}$ & $7,4 \mathrm{a}$ \\
\hline \multicolumn{7}{|l|}{$\mathrm{N}\left(\mathrm{kg} \mathrm{ha}^{-1}\right)$} \\
\hline 0 & 5,03 & 6,50 & 35,4 & 29,8 & 10,5 & 6,9 \\
\hline 30 & 5,94 & 6,84 & 34,7 & 30,5 & 11,0 & 6,8 \\
\hline 60 & 6,25 & 7,17 & 34,7 & 31,2 & 11,4 & 6,4 \\
\hline 90 & 6,38 & 7,50 & 35,4 & 32,0 & 10,3 & 7,1 \\
\hline 120 & 6,83 & 7,84 & 36,7 & 32,7 & 11,0 & 7,3 \\
\hline $\mathrm{CV}(\%)$ & 19,64 & 26,21 & 10,11 & 14,51 & 26,13 & 21,80 \\
\hline
\end{tabular}

${ }^{(1)}$ Médias seguidas por letras iguais não diferem entre si pelo teste de Tukey a $5 \%$ de probabilidade. ${ }^{(2)}$ L1: coeficiente da cultura $\left(\right.$ Kc $\left._{1}\right)+$ precipitação; L2: $\mathrm{Kc}_{2}+$ precipitação; L3: $\mathrm{Kc}_{3}+$ precipitação. 
seca de plantas, ocorrendo assim um efeito de concentração do nutriente nas plantas. $\mathrm{O}$ aumento nas doses de $\mathrm{N}$ propiciou variações nos teores desse nutriente na planta e os dados se ajustaram a uma função quadrática $\left(y=35,3563-0,0318 x+0,00036 x^{2}\right)$ em 2001 e linear $(y=29,7689+0,0244 x)$ em 2002. Entretanto, mesmo no tratamento testemunha (sem $\mathrm{N}$ em cobertura) os valores encontrados estão na faixa adequada para a cultura, ou seja, 30 a $50 \mathrm{~g} \mathrm{~kg}^{-1}$ (Ambrosano et al., 1996). Silveira \& Damasceno (1993), estudando a aplicação de doses de $\mathrm{N}$ na cultura do feijoeiro irrigado por pivô

Tabela 4. Massa de matéria seca de plantas de feijoeiro cultivadas sob diferentes lâminas de água aplicadas por aspersão e doses de $\mathrm{N}$ aplicadas em cobertura, em $2001^{(1)}$.

\begin{tabular}{cccc}
\hline $\mathrm{N}$ & \multicolumn{3}{c}{ Lâminas de água $^{(2)}$} \\
\cline { 2 - 4 }$\left(\mathrm{kg} \mathrm{ha}^{-1}\right)$ & $\mathrm{L} 1$ & $\mathrm{L2}^{(3)}$ & $\mathrm{L} 3^{(4)}$ \\
\hline 0 & $6,07 \mathrm{~A}$ & $4,54 \mathrm{~B}$ & $4,48 \mathrm{~B}$ \\
30 & $7,19 \mathrm{~A}$ & $5,43 \mathrm{~B}$ & $5,20 \mathrm{~B}$ \\
60 & $6,75 \mathrm{~A}$ & $6,31 \mathrm{~A}$ & $5,67 \mathrm{~A}$ \\
90 & $6,89 \mathrm{~A}$ & $6,19 \mathrm{~A}$ & $6,09 \mathrm{~A}$ \\
120 & $6,70 \mathrm{AB}$ & $7,48 \mathrm{~A}$ & $6,31 \mathrm{~B}$ \\
\hline
\end{tabular}

${ }^{(1)}$ Médias seguidas de letras diferentes, na linha, diferem entre si pelo teste de Tukey a 5\% de probabilidade. ${ }^{(2)} \mathrm{L} 1$ : coeficiente da cultura $\left(\mathrm{Kc}_{1}\right)+$ precipitação; $\mathrm{L} 2: \mathrm{Kc}_{2}+$ precipitação; $\mathrm{L} 3: \mathrm{Kc}_{3}+$ precipitação. (3) $\mathrm{y}=4,6630+0,0221 \mathrm{x} \quad\left(\mathrm{R}^{2}=0,92\right) . \quad{ }^{(4)} \mathrm{y}=4,6403+0,0151 \mathrm{x}$ $\left(\mathrm{R}^{2}=0,96\right)$. central, também verificaram que houve aumento da massa de matéria seca de plantas, teor e conteúdo de $\mathrm{N}$ na parte aérea da planta com o aumento da dose desse nutriente aplicada ao solo. A resposta dessas variáveis ao $\mathrm{N}$ é dependente do teor de $\mathrm{N}$ disponível no solo, proveniente da mineralização da matéria orgânica, temperatura, fixação simbiótica de $\mathrm{N}_{2}$, cultivar e outros.

$\mathrm{O}$ número de vagens e o número de grãos por planta foram influenciados apenas pelo preparo do solo, e os menores valores foram obtidos no plantio direto. Esse comportamento pode ser explicado pela ocorrência de mofo-branco na área de cultivo, pois o ataque foi mais intenso nas parcelas com plantio direto. A aplicação de doses de $\mathrm{N}$ em cobertura afetou significativamente apenas o número de grãos por planta no segundo ano de cultivo e os dados se ajustaram a uma função linear $\mathrm{y}=31,966+0,0387 \mathrm{x}$.

$\mathrm{O}$ número de grãos por vagem foi influenciado, em 2001, pelas doses de $\mathrm{N}$ aplicadas em cobertura e os dados se ajustaram a uma equação linear $\mathrm{y}=4,6761+$ 0,003x (Tabela 5). Em 2002 houve interação significativa entre lâminas de água e preparo do solo (Tabela 6). $\mathrm{Na}$ lâmina $\mathrm{L}_{1}$ o plantio direto apresentou o maior número de grãos por vagem. Ainda no plantio direto, a lâmina $\mathrm{L}_{1}$ apresentou maior número de grãos por vagem em relação à lâmina $\mathrm{L}_{3}$. Os demais tratamentos não diferi-

Tabela 5. Número de grãos por planta, número de grãos por vagem, massa de 100 grãos e produtividade de grãos em feijoeiro de inverno em razão de diferentes lâminas de água aplicadas por aspersão, de diferentes preparos do solo e de doses de $\mathrm{N}$ aplicadas em cobertura. Selvíria, MS, 2001 e $2002^{(1)}$.

\begin{tabular}{|c|c|c|c|c|c|c|c|c|}
\hline \multirow[t]{2}{*}{ Tratamento } & \multicolumn{2}{|c|}{$\begin{array}{l}\text { Número de grãos } \\
\text { por planta }\end{array}$} & \multicolumn{2}{|c|}{$\begin{array}{l}\text { Número de grãos } \\
\text { por vagem }\end{array}$} & \multicolumn{2}{|c|}{$\begin{array}{l}\text { Massa de } 100 \\
\text { grãos (g) }\end{array}$} & \multicolumn{2}{|c|}{$\begin{array}{l}\text { Grãos } \\
\left(\mathrm{kg} \mathrm{ha}^{-1}\right)\end{array}$} \\
\hline & 2001 & 2002 & 2001 & 2002 & 2001 & 2002 & 2001 & 2002 \\
\hline \multicolumn{9}{|l|}{ Lâminas de água ${ }^{(2)}$} \\
\hline L1 & $53,2 \mathrm{a}$ & $35,3 \mathrm{a}$ & $4,9 \mathrm{a}$ & $5,1 \mathrm{a}$ & $23,16 a b$ & $21,23 a$ & $1.970 \mathrm{a}$ & $1.598 \mathrm{a}$ \\
\hline L2 & $51,0 \mathrm{a}$ & $35,3 a$ & $4,9 \mathrm{a}$ & $5,0 \mathrm{a}$ & $23,08 \mathrm{a}$ & $21,17 \mathrm{a}$ & $1.854 \mathrm{a}$ & $1.618 \mathrm{a}$ \\
\hline L3 & $52,8 \mathrm{a}$ & $32,2 \mathrm{a}$ & $4,8 \mathrm{a}$ & $4,9 \mathrm{a}$ & $22,54 \mathrm{~b}$ & $21,17 \mathrm{a}$ & $1.908 \mathrm{a}$ & $1.523 \mathrm{a}$ \\
\hline \multicolumn{9}{|l|}{ Preparo do solo } \\
\hline Plantio direito & $48,7 \mathrm{a}$ & $32,1 b$ & $4,9 \mathrm{a}$ & $5,1 \mathrm{a}$ & $23,08 \mathrm{a}$ & $21,35 \mathrm{a}$ & $1.809 b$ & $1.430 \mathrm{~b}$ \\
\hline Grade pesada & $54,5 \mathrm{a}$ & $34,6 a b$ & $4,8 \mathrm{a}$ & $5,0 \mathrm{a}$ & $23,23 \mathrm{a}$ & $21,23 a$ & $1.891 \mathrm{ab}$ & $1.614 \mathrm{a}$ \\
\hline Arado de aiveca & $53,5 \mathrm{a}$ & $36,1 \mathrm{a}$ & $4,8 \mathrm{a}$ & $4,9 \mathrm{a}$ & $22,47 b$ & $20,98 \mathrm{a}$ & $2.032 \mathrm{a}$ & $1.695 \mathrm{a}$ \\
\hline \multicolumn{9}{|l|}{$\mathrm{N}\left(\mathrm{kg} \mathrm{ha}^{-1}\right)$} \\
\hline 0 & 50,4 & 31,9 & 4,7 & 4,9 & 22,75 & 21,15 & 1.753 & 1.599 \\
\hline 30 & 51,6 & 33,1 & 4,8 & 4,9 & 22,87 & 20,96 & 1.931 & 1.530 \\
\hline 60 & 53,2 & 34,3 & 4,9 & 5,0 & 22,97 & 21,23 & 1.908 & 1.602 \\
\hline 90 & 52,1 & 35,4 & 4,9 & 5,1 & 22,97 & 21,21 & 1.943 & 1.556 \\
\hline 120 & 54,1 & 36,6 & 5,0 & 5,1 & 23,31 & 21,40 & 2.020 & 1.612 \\
\hline $\mathrm{CV}(\%)$ & 26,63 & 26,61 & 12,97 & 15,42 & 3,98 & 4,91 & 20,61 & 18,13 \\
\hline
\end{tabular}

${ }^{(1)}$ Para cada variável, médias seguidas pela mesma letra, não diferem entre si a 5\% de probabilidade, pelo teste de Tukey. ${ }^{(2)}$ L1: coeficiente da cultura $\left(\mathrm{Kc}_{1}\right)+$ precipitação; L2: $\mathrm{Kc}_{2}+$ precipitação; L3: $\mathrm{Kc}_{3}+$ precipitação. 
ram significativamente entre si. O número de grãos por vagem, mesmo sendo uma característica mais relacionada com a cultivar, foi influenciado pelo aumento das doses de N, pelo manejo do solo e pela irrigação. Isso indica que uma melhor nutrição em $\mathrm{N}$, por exemplo, pode aumentar o número de óvulos fertilizados por vagem.

Quanto à massa de 100 grãos houve influência dos tratamentos apenas no primeiro ano de cultivo. $\mathrm{O}$ desdobramento da interação entre lâmina de água e preparo do solo revelou que na lâmina $\mathrm{L}_{1}$ o preparo do solo com grade aradora propiciou maior massa de 100 grãos e na lâmina $\mathrm{L}_{3}$ esse comportamento ocorreu no tratamento em sistema de plantio direto (Tabela 6). Nas lâminas de água dentro de preparo do solo, verifica-se que houve efeito no preparo do solo com grade aradora e com arado de aiveca, em que a massa de 100 grãos diminuiu com o aumento das lâminas de água. É possível que, nesses tipos de preparo de solo, o aumento da disponibilidade hídrica obtida pelo aumento da lâmina de água tenha propiciada condições de menor aeração no solo, interferindo na produção de fotoassimilados para o enchimento dos grãos. Resultado semelhante ocorreu com a massa de matéria seca de plantas, ou seja, houve uma diminuição da massa de matéria seca com o aumento da disponibilidade de água no solo. Isto pode ser devido ao fato de que uma menor massa de plantas pode produzir menor quantidade de fotoassimilados, o que pode se traduzir numa menor massa de grãos e, conseqüentemente menor produtividade. De acordo com Pedroso \& Corsini (1983), no preparo convencional do solo as operações são realizadas continuamente na mesma pro-

Tabela 6. Número de grãos por vagem (2002) e massa de 100 grãos (2001) de feijoeiro em razão de diferentes lâminas de água aplicadas por aspersão e diferentes preparo do solo. Selvíria, $\mathrm{MS}^{(1)}$.

\begin{tabular}{lccc}
\hline \multirow{2}{*}{$\begin{array}{l}\text { Preparo } \\
\text { do solo }\end{array}$} & \multicolumn{3}{c}{ Lâminas de água $^{(2)}$} \\
\cline { 2 - 4 } & $\mathrm{L} 1$ & $\mathrm{L2}^{(3)}$ & $\mathrm{L3}^{(4)}$ \\
\hline \multirow{2}{*}{ Plantio direto } & $5,4 \mathrm{aA}$ & $5,0 \mathrm{aAB}$ & $4,8 \mathrm{aB}$ \\
Grade aradora & $4,8 \mathrm{bA}$ & $5,1 \mathrm{aA}$ & $5,2 \mathrm{aA}$ \\
Arado de aiveca & $4,9 \mathrm{abA}$ & $5,0 \mathrm{aA}$ & $4,8 \mathrm{aA}$ \\
\hline \multicolumn{4}{c}{ Massa de 100 grãos $(\mathrm{g})$} \\
Plantio direto & $22,79 \mathrm{bA}$ & $23,31 \mathrm{~A}$ & $4,8 \mathrm{aB}$ \\
Grade aradora & $23,71 \mathrm{aA}$ & $23,29 \mathrm{AB}$ & $5,2 \mathrm{aA}$ \\
Arado de aiveca & $22,79 \mathrm{bA}$ & $22,64 \mathrm{~A}$ & $4,8 \mathrm{aA}$ \\
\hline
\end{tabular}

${ }^{(1)}$ Médias seguidas de letras diferentes, minúsculas nas colunas e maiúsculas nas linhas, diferem entre si pelo teste de Tukey a $5 \%$ de probabilidade. ${ }^{(2)} \mathrm{L} 1$ : coeficiente da cultura $\left(\mathrm{Kc}_{1}\right)+$ precipitação; $\mathrm{L} 2: \mathrm{Kc}_{2}+$ precipitação; $\mathrm{L} 3: \mathrm{Kc}_{3}+$ precipitação. fundidade, podendo ocasionar em alguns tipos de solo uma camada compactada resultante da pressão do arado como também da grade. Esse efeito pode ter ocorrido na área experimental utilizada, pois a compactação do solo tem efeito marcante sobre a aeração em razão das modificações que provoca na estrutura do solo e na drenagem da água. Pois, segundo Moreira et al. (1988), o excesso de água no solo provoca deficiência de oxigênio, levando a uma concentração inadequada deste nutriente na planta e redução da atividade microbiana do solo.

As lâminas de água utilizadas não alteraram a produtividade de grãos, mesmo com uma diferença de aproximadamente $100 \mathrm{~mm}$ de água durante o ciclo da cultura, proveniente das chuvas e irrigação, entre os tratamentos com as lâminas $\mathrm{L}_{1}$ e $\mathrm{L}_{3} \mathrm{em} 2002$ (Tabela 5). A irrigação foi suspensa ainda no final da fase $R_{8}$, em razão da ocorrência de mofo-branco na área de cultivo. Possivelmente a interrupção da irrigação, nessa fase, tenha interferido no enchimento completo dos grãos, pois a massa de 100 grãos em 2002 foi, em média, de 21,19 g, portanto, inferior aos valores normalmente obtidos por essa cultivar em condições normais de cultivo o que deve ter contribuído para a obtenção de uma baixa produtividade média na época de cultivo.

$\mathrm{Na}$ lâmina $\mathrm{L}_{1}$ foi utilizado menor volume de água de irrigação, comparativamente às lâminas $\mathrm{L}_{2}$ e $\mathrm{L}_{3}$. Em 2002, a economia de água foi de aproximadamente $35 \%$ e 47\%, ou seja, 63 e $104 \mathrm{~mm}$, respectivamente, em relação às lâminas $\mathrm{L}_{2} \mathrm{e} \mathrm{L}_{3}$. Em ambas situação a produtividade de grãos foi semelhante.

De acordo com Doorenbos \& Kassam (1979), a necessidade de água para o feijoeiro com 60 a 120 dias varia de 300 a $500 \mathrm{~mm}$ para obtenção de alta produtividade de grãos, e no presente trabalho, mesmo na lâmina $\mathrm{L}_{3}$, a quantidade total de água fornecida para a cultura durante o período de cultivo foi inferior a $300 \mathrm{~mm}$. É possível que, para a faixa de produtividade de grãos obtida, mesmo com quantidade de água inferior à indicada pelos autores, as necessidades mínimas da cultura tenham sido atendidas em razão do cultivo ter sido realizado no período de inverno no qual os dias são mais curtos e as temperaturas mais amenas, propiciando menores perdas de água por evapotranspiração. Moreira et al. (1988) citam que o consumo de água pelo feijoeiro depende do estádio de desenvolvimento das plantas, condições do solo, época de cultivo e das condições climáticas. O preparo do solo com arado de aiveca e o 
com grade aradora apresentaram maior produtividade de grãos em relação ao plantio direto. No plantio direto houve um maior ataque de mofo-branco em relação aos tratamentos com revolvimento do solo. Uma das medidas preventivas de controle da doença é o enterrio profundo de restos culturais e no plantio direto os restos culturais foram mantidos na superfície do solo, criando condições favoráveis para ocorrência dessa doença.

Não foi observado também efeito da interação entre o preparo do solo e as lâminas de água na produtividade de grãos, discordando dos dados de Barros \& Hanks (1997). Esses autores observaram que a cobertura do solo foi efetiva no aumento da produtividade e da eficiência do uso de água pelo feijoeiro em todos os níveis de irrigação testados. A aplicação de $\mathrm{N}$ em cobertura não propiciou aumento significativo na produtividade de grãos nos dois anos de cultivo. Ferreira (1998) também não observou efeito de doses de $\mathrm{N}$ nos componentes da produção e na produtividade de grãos do feijoeiro cultivado no período de inverno. Já Buzetti et al. (1992) observaram que o aumento nas doses de $\mathrm{N}$ aumentou linearmente a produtividade, ou seja, $4,33 \mathrm{~kg}$ de grãos de feijão para cada kg de $\mathrm{N}$ aplicado. Carvalho et al. (2001), também no Município de Selvíria, MS, estudando o efeito de fontes e diferentes parcelamentos do $\mathrm{N}$ em feijoeiro de inverno, concluíram que a aplicação de $75 \mathrm{~kg} \mathrm{ha}^{-1}$ de $\mathrm{N}$ proporcionou, em média, incrementos de $38 \%$ na produtividade da cultura.

A falta de resposta à aplicação de $\mathrm{N}$ em cobertura deve-se, provavelmente, ao fornecimento do nutriente pelo solo aliado a fixação do $\mathrm{N}$ atmosférico por bactérias nativas, pois, embora não tenha sido realizada a inoculação de sementes, verificou-se a presença de nódulos no sistema radicular das plantas de feijão na área de cultivo. $\mathrm{O} N$ não foi fator limitante ao desenvolvimento da cultura, pois mesmo no tratamento testemunha, o teor de $\mathrm{N}$ nas plantas se encontrava dentro dos níveis considerados adequados para o feijoeiro, ou seja, 30 a $50 \mathrm{~g} \mathrm{~kg}^{-1}$ em folhas, no período do florescimento das plantas, conforme Ambrosano et al. (1996).

\section{Conclusões}

1. O tratamento com a menor lâmina de água propicia produtividade de grãos semelhante aos tratamentos com maiores lâminas de água e, conseqüentemente, menor custo de irrigação.

2. O preparo do solo com arado de aiveca propicia maior produtividade de grãos em relação ao plantio direto e produtividade semelhante à obtida no preparo com grade aradora.
3. A adubação nitrogenada em cobertura não afeta a produtividade de grãos do feijoeiro irrigado por aspersão.

\section{Agradecimentos}

À Fapesp e ao CNPq pelo financiamento da pesquisa.

\section{Referências}

AMBROSANO, J.E.; WUTKE, E.B.; CANTARELLA, H. Feijão. In: RAIJ, B. van; CANTARELLA, H.; QUAGGIO, J.A.; FURLANI, A.M.C. (Ed.). Recomendações de adubação e calagem para o Estado de São Paulo. 2.ed. Campinas: Instituto Agronômico, 1996. p.194-195.

BARROS, L.C.G.; HANKS, J. Evapotranspiration and yield of beans affected by mulch and irrigation. Agronomy Journal, v.85, p.692697, 1997.

BERGAMASCHI, H.; VIEIRA, H.J.; OMETO, J.C.; ANGELOCCI, L.R.; LIBARDI, P.L. Deficiência hídrica em feijoeiro - I: análise de crescimento e fenologia. Pesquisa Agropecuária Brasileira, v.23, p.733-743, 1988.

BUZETTI, S.; ROMEIRO, P.J.M.; ARF, O.; SÁ, M.E.; GUERREIRO NETO, G. Efeito da adubação nitrogenada em componentes da produção do feijoeiro (Phaseolus vulgaris L.) cultivado em diferentes densidades. Cultura Agronômica, v.1, p.1119, 1992.

CARVALHO, M.A.C.; ARF, O.; SÁ, M.E.; BUZETTI, S.; SANTOS, N.C.B.; BASSAN, D.A.Z. Produtividade e qualidade de sementes de feijoeiro (Phaseolus vulgaris L.) sob influência de parcelamentos e fontes de nitrogênio. Revista Brasileira de Ciência do Solo, v.25, p.617-624, 2001.

CASTRO, O.M.; VIEIRA, S.R.; MARIA, I.C. Sistema de preparo do solo e disponibilidade de água. In: SIMPÓSIO SOBRE MANEJO DE ÁGUA NA AGRICULTURA, 1987, Campinas. Anais. Campinas: Fundação Cargill, 1987. p.27-51.

DOORENBOS, J.; KASSAM, A.H. Yield response to water. Roma: FAO, 1979. 193p. (Irrigation and Drainage Paper, 33).

DOORENBOS, J.; PRUITT, W.O. Las necesidades de agua de los cultivos. Roma: FAO, 1976. 194p. (Estúdio FAO Riego y Drenage, 24).

EMBRAPA. Centro Nacional de Pesquisa de Solos (Rio de Janeiro, RJ). Sistema brasileiro de classificação de solos. Brasília: Embrapa-SPI; Embrapa-CNPS, 1999. 412p.

FERNANDEZ, F.; GEPTS, P.; LOPES, M. Etapas de desarrollo de la planta de frijol (Phaseolus vulgaris L.). Cali: Centro Internacional de Agricultura Tropical, 1986. 34p.

FERREIRA, E.C. Efeito de doses e parcelamento da adubação nitrogenada em cobertura na cultura do feijão (Phaseolus vulgaris L.). 1998. 30p. Monografia (Graduação) - Universidade Estadual Paulista, Ilha Solteira.

FORNASIERI FILHO, D.; FORNASIERI, J.L. Manual da cultura do arroz. Jaboticabal: Funep, 1993. 221p. 
KATTAN, A.A.; FLEMING, J.W. Effect of irrigation at specific stages of development on yield, quality growth and composition of snap beans. Proceedings of the American Society for Horticultural Science, v.68, p.329-342, 1956.

Mac KAY, D.C.; EANES, C.A. Influence of irrigation treatments on yields and on fertilization by sweet corn and snap beans. Journal of Plant Science, v.42, p.219-228, 1962.

MOREIRA, J.A.A.; AZEVEDO, J.A.; STONE, L.F.; CAIXETA, T.J. Irrigação. In: ZIMMERMANN, M.I.O.; ROCHA, M.; YAMADA, T. (Ed.). Cultura do feijoeiro: fatores que afetam a produtividade. Piracicaba: Associação Brasileira para Pesquisa da Potassa e do Fosfato, 1988. p.317-340.

PEDROSO, P.A.C.; CORSINI, P.C. Manejo físico do solo. In: FERREIRA, M.E.; YAMADA, T.; MALAVOLTA, E. (Ed.). Cultura do arroz de sequeiro: fatores afetando a produtividade. Piracicaba: Associação Brasileira para Pesquisa da Potassa e do Fosfato, 1983. p.225-238.

SARRUGE, J.R.; HAAG, H.P. Análises químicas em plantas. Piracicaba: Esalq, 1974. 56p.

SILVEIRA, P.M.; DAMASCENO, M.A. Doses e parcelamento de $\mathrm{K}$ e de $\mathrm{N}$ na cultura do feijoeiro irrigado. Pesquisa Agropecuária Brasileira, v.28, p.1269-1276, 1993.

SILVEIRA, P.M.; STONE, L.F. Irrigação. In: VIEIRA, C.; PAULA JÚNIOR, T.J.; BORÉM, A. (Ed.). Feijão: aspectos gerais e cultura no Estado de Minas. Viçosa, MG: UFV, 1998. p.181-220.

STONE, L.F.; SILVEIRA, P.M. Efeitos do sistema de preparo na compactação do solo, disponibilidade hídrica e comportamento do feijoeiro. Pesquisa Agropecuária Brasileira, v.34, p.83-91, 1999.

Recebido em 13 de março de 2003 e aprovado em 20 de janeiro de 2004 
